\title{
Novas Moléculas Pequenas para Optoeletrónica
}

Vasco Bonifácio

vasco.bonifacio@tecnico.ulisboa.pt
- - O desenvolvimento de dispositivos optoeletrónicos mais eficientes tem despertado um grande interesse tanto na área da química como na área da ciência dos materiais, tendo em vista uma miríade de aplicações, particularmente na eletrónica flexível. Os semicondutores orgânicos (OSCs) oferecem características exclusivas, tais como uma estrutura eletrónica e propriedades físico-químicas ajustáveis, funcionalidade, flexibilidade mecânica, e também hiatos óticos variáveis. Comparados com os seus equivalentes inorgânicos, os OSCs podem ser processados em grande escala e com baixo custo. Os transístores orgânicos de filme fino (OTFTs) e os díodos orgânicos emissores de luz (OLEDs) são particularmente importantes por constituírem os elementos-base de dispositivos eletrónicos e optoeletrónicos. Recentemente, desenvolvemos uma nova família de OSCs baseada num núcleo bisamida pentacíclico (ChemComm 2020, 56, 14893-14896).
Quer os testes físico-químicos quer os testes in silico (cálculos DFT de parâmetros críticos) mostraram o enorme potencial de condução eletrónica e emissão de luz destes compostos. Este trabalho deu origem a uma patente nacional (PT116848) e foi alvo de uma comunicação oral no ACS Spring Meeting 2021. Utilizando metodologias sustentáveis pretendemos preparar mais compostos desta família, com melhores propriedades de condução eletrónica e absorção e emissão de luz no UV próximo e visível. Para concretizar este objetivo, é necessário adotar uma abordagem integrada da relação entre estrutura molecular e supramolecular, estudar em detalhe as suas propriedades eletroquímicas e fotofísicas, e avaliar o desempenho dos dispositivos. 0 objetivo principal deste projeto é a construção de dispositivos eletrónicos e optoeletrónicos otimizados, em termos de eficiência, custo e sustentabilidade relativamente aos que já existem no mercado.
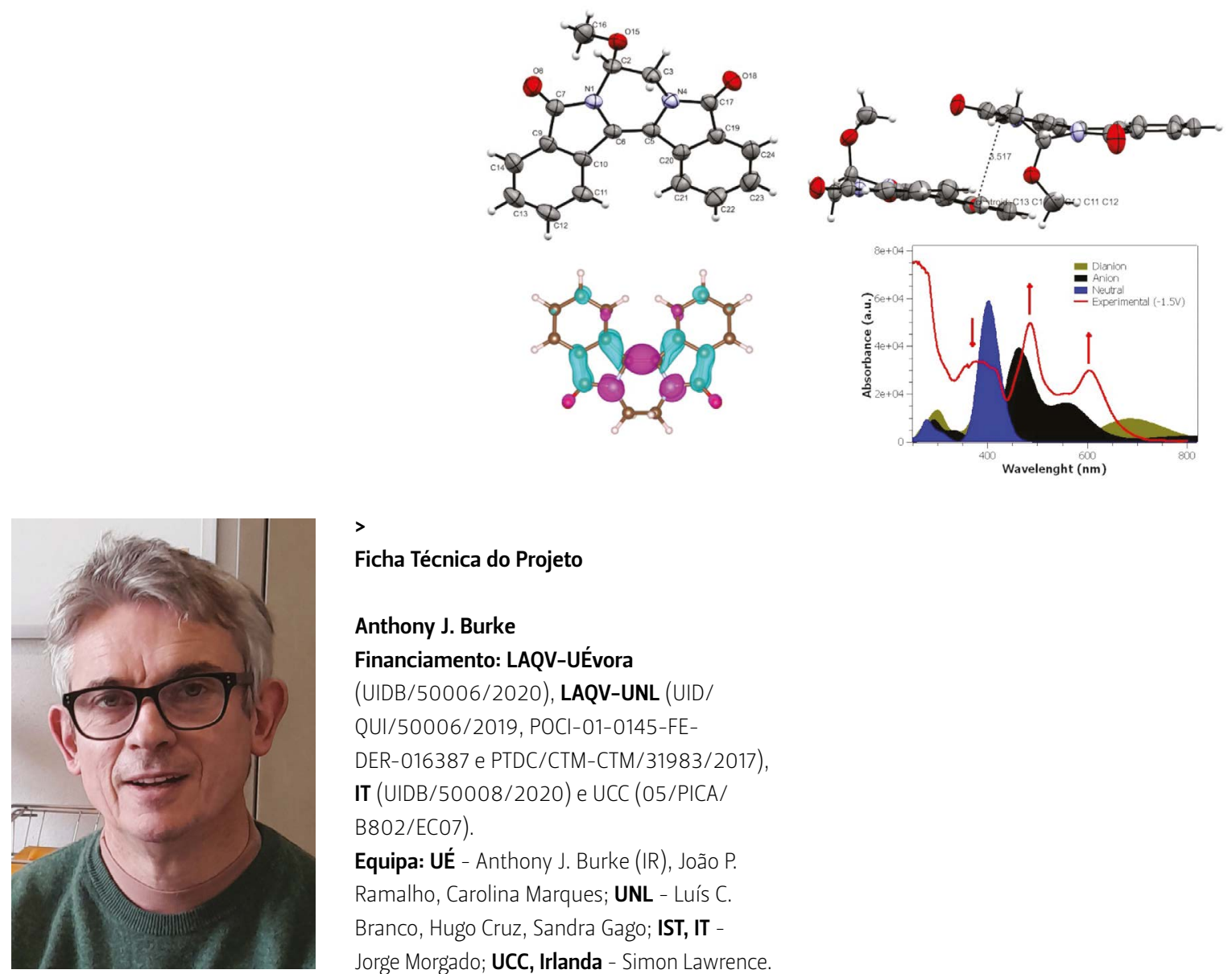

Ficha Técnica do Projeto

\section{Anthony J. Burke}

Financiamento: LAQV-UÉvora

(UIDB/50006/2020), LAQV-UNL (UID/

QUI/50006/2019, POCl-01-0145-FE-

DER-016387 e PTDC/CTM-CTM/31983/2017),

IT (UIDB/50008/2020) e UCC (05/PICA/

B802/EC07).

Equipa: UÉ - Anthony J. Burke (IR), João P.

Ramalho, Carolina Marques; UNL - Luís C.

Branco, Hugo Cruz, Sandra Gago; IST, IT -

Jorge Morgado; UCC, Irlanda - Simon Lawrence. 